\title{
Effects of continuous and intermittent carbon dioxide enrichment on fruit set and yield of sweet pepper (Capsicum annuum L.)
}

\author{
E. M. Nederhoff and J. A. M. van Uffelen
}

Glasshouse Crops Research Station, P.O. Box 8, NL 2670 AA Naaldwijk, Netherlands

Received 23 December 1987; accepted 5 April 1988

Key words: Capsicum annuum, sweet pepper, carbon dioxide, intermittent $\mathrm{CO}_{2}$ enrichment

\begin{abstract}
The effects of carbon dioxide $\left(\mathrm{CO}_{2}\right)$ enrichment on vegetative growth, fruit set and yield of an autumn crop of sweet pepper (Capsicum annuum L., cv. Bolero) were studied. In 12 greenhouse compartments of $9.6 \mathrm{~m} \times 6 \mathrm{~m}$ each, $6 \mathrm{CO}_{2}$ treatments were tested: 3 continuous $\mathrm{CO}_{2}$ levels, setpoints 200,340 and $500 \mathrm{ppm}\left(\mu \mathrm{l}^{-1}\right), 2$ intermittent dosings ( 8 minutes per 40 and per 104 minutes, respectively) and a control (without dosing or filtering). It was not possible to maintain the setpoints of the continuous $\mathrm{CO}_{2}$ levels throughout the experiment, therefore the measured $\mathrm{CO}_{2}$ concentrations were used to explain the effects.

The results show a positive effect of elevated $\mathrm{CO}_{2}$ concentrations on fruit set and yield. The number of fruits harvested per $\mathrm{m}^{2}$ was $60 \%$ higher at the $500 \mathrm{ppm}$ treatment than at the $200 \mathrm{ppm}$ treatment, whereas the average fruit weight was not significantly affected. The dry matter content of the leaves increased, the SLA and LAR were smaller at higher $\mathrm{CO}_{2}$ concentrations. The vegetative growth tended to decrease at higher $\mathrm{CO}$, levels, which was ascribed to competition between vegetative and generative organs. The results with respect to the setting and yield were less favourable at intermittent $\mathrm{CO}_{2}$ enrichment than at continuous $\mathrm{CO}_{2}$ levels, if plotted versus the measured, average $\mathrm{CO}_{2}$ concentration.
\end{abstract}

\section{Introduction}

Carbon dioxide $\left(\mathrm{CO}_{2}\right)$ has a strong positive effect on the productivity of greenhouse crops (Kimball, 1986). Not much specific literature is available however, about the effect of $\mathrm{CO}_{2}$ on sweet pepper under greenhouse conditions, especially in an autumn crop. The planting date of such a crop in the Netherlands varies from the end of June to August. A problem in this growing period is the poor fruit set and low 
yield. Fruit set is especially problematic during periods of calm, dull weather, which are not unusual in autumn.

The hypothesis is that the supply with assimilates may be limiting for fruit set as suggested by various authors (Calvert \& Slack, 1975; Acock \& Pasternak, 1986). Under dull weather conditions, the $\mathrm{CO}_{2}$ concentration can become very low due to a low $\mathrm{CO}_{2}$ influx. The question to be answered was whether $\mathrm{CO}_{2}$ enrichment stimulates the setting and the productivity of autumn greenhouse sweet pepper.

Since several years it is common practice in modern greenhouse crop production to enrich the greenhouse air with carbon dioxide. In the Dutch greenhouse industry this is mostly done with exhaust gases from the (central) heating system (van Berkel, 1986). $\mathrm{CO}_{2}$ enrichment is then connected with the production of heat, which is a disadvantage in the warmer seasons. Moreover, when ventilation increases, the efficiency of $\mathrm{CO}_{2}$ enrichment decreases. Due to these two conditions, the $\mathrm{CO}_{2}$ supply is at a low level during late summer and early autumn.

In order to reduce the costs and increase the efficiency of enrichment, a technique with pulsed or intermittent dosing was suggested by Enoch (1984). According to Mortensen (1984), plants respond more efficiently to intermittent $\mathrm{CO}_{2}$ enrichment than to a continuous $\mathrm{CO}_{2}$ level, probably because adaptation of the plants to high $\mathrm{CO}_{2}$ levels is prevented.

In the experiment reported here, different $\mathrm{CO}_{2}$ treatments were chosen, such that the effect of $\mathrm{CO}_{2}$ shortage $(200 \mathrm{ppm})$ as well as of $\mathrm{CO}_{2}$ enrichment $(500 \mathrm{ppm})$ could be compared with the average ambient $\mathrm{CO}_{2}$ level $(340 \mathrm{ppm})$ and with a treatment without enrichment or filtering. In addition, the principle of intermittent en-' richment was tested, although in a different set-up than suggested by Enoch (1984).

To be able to study the $\mathrm{CO}_{2}$ effect under various weather types (including the unfavourable conditions), fruit set was allowed on several dates in the cultivation.

\section{Materials and methods}

\section{Experimental set-up}

The experiment has been carried out in twelve compartments of a Venlo-type greenhouse of $9.6 \mathrm{~m} \times 6 \mathrm{~m}$ each. Sweet pepper (Capsicum annuum L., cv. Bolero), was planted in soil on 15 July 1985. Carbon dioxide enrichment started on 1 August. Harvesting started on 1 October and was finished on 19 November. The young plants were first kept vegetative by weekly defloration/defruiting (removing all set flowers and young fruits) until the date that fruit set was allowed. Four different dates for the start of fruit set were applied at four different groups of plants: 5, 13, 21 and 29 August (in each compartment the same four fruit set dates in duplicate). The results on fruit set (Table 3) are given separately per fruit set date and the results on yield (Table 4, Figs. 1 and 2 ) are given for all fruit set dates combined.

Climate control was done by a minicomputer. Except for the $\mathrm{CO}_{2}$ concentrations, the climatic conditions maintained in the experimental greenhouse were comparable to those in commercial greenhouses and equal in all compartments. Setpoint for heating was $21{ }^{\circ} \mathrm{C}$ by day and $15{ }^{\circ} \mathrm{C}$ at night. The temperatures at 
which ventilation started, were set two degrees above the heating setpoint. This relatively high dead zone was applied in order to decrease (unnecessary) $\mathrm{CO}_{2}$ losses. During the whole period, a small ventilation (minimum of $5 \%$ of the window opening) was maintained.

\section{Carbon dioxide treatments}

In the experiment the following six $\mathrm{CO}_{2}$ treatments were applied:

(1) continuous $\mathrm{CO}_{2}$ level of $200 \mathrm{ppm}\left(\mu \mathrm{I}^{-1}\right)$;

(2) continuous $\mathrm{CO}_{2}$ level of $340 \mathrm{ppm}$;

(3) continuous $\mathrm{CO}_{2}$ level of $500 \mathrm{ppm}$;

(4) intermittent $\mathrm{CO}_{2}$ dosing, one $\mathrm{CO}_{2}$ pulse of 8 minutes per 40 minutes;

(5) intermittent $\mathrm{CO}_{2}$ dosing, one $\mathrm{CO}_{2}$ pulse of 8 minutes per 104 minutes:

(6) control treatment, without dosing or filtering.

In the treatments with pulsed $\mathrm{CO}_{2}$, the flux of $\mathrm{CO}_{2}$ was adapted, so that in 8 minutes the concentration rose to about 400 to $800 \mathrm{ppm}$ (depending on the ventilation).

The six $\mathrm{CO}_{2}$ treatments were applied in duplicate: one replicate in a compartment with the front wall facing north, the other replicate in a south orientated compartment. In all treatments, $\mathrm{CO}_{2}$ was supplied and controlled only during daytime.

The $\mathrm{CO}_{2}$ concentration was measured with a $\mathrm{CO}_{2}$ analyser (Siemens), combined with a multiplexer. Eight compartments were measured by one device with a measuring cycle of 8 minutes. The dosing of liquid $\mathrm{CO}_{2}$ from a storage tank and, in the treatment with $200 \mathrm{ppm}$, filtering of the air through a chemical filter $(\mathrm{NaOH}+$ $\mathrm{Ca}(\mathrm{OH})_{2}$ ) to remove $\mathrm{CO}_{2}$, were controlled by a minicomputer.

\section{Observations}

Recorded data on environmental conditions were: $\mathrm{CO}_{2}$ concentration, temperature and window aperture of each compartment, windspeed and light intensity (Photosynthetically Active Radiation) outside. Except for the $\mathrm{CO}_{2}$ concentration which had a measuring cycle of 8 minutes, the other factors were measured and recorded each minute. Observations on the crop were:

- fruit set: removed set flowers were counted on 13,21 and 29 August;

- yield: every week the ripe, red fruits were harvested, weighed and counted. At the end of the season (19 November) all mature fruits were harvested (green or red/ green mature fruits separated from the red ones);

- vegetative plant parameters: on five dates two plants per compartment were sampled. Number of leaves, leaf area, fresh and dry weights of leaves and stems were recorded.

\section{Results}

\section{$\mathrm{CO}_{2}$ concentration}

Table 1 shows the average, measured $\mathrm{CO}_{2}$ concentrations during daylight hours. It 
Table 1. $\mathrm{CO}_{2}$ concentrations $\left(\mu 11^{-1}\right)$ measured at the six $\mathrm{CO}_{2}$ treatments during daylight hours, averaged per period and averaged over the two replicates.

\begin{tabular}{|c|c|c|c|c|c|c|c|c|}
\hline \multirow[t]{2}{*}{ Date } & \multicolumn{4}{|c|}{ Continuous $\mathrm{CO}_{2}$ levels } & \multicolumn{2}{|c|}{ Intermittent } & \multirow[t]{2}{*}{ Control } & \multirow{2}{*}{$\begin{array}{l}\mathrm{LSD}^{2} \\
(P<0.05)\end{array}$} \\
\hline & $200 \mathrm{ppm}$ & $340 \mathrm{ppm}$ & $500 \mathrm{ppm}$ & ANOVA $^{1}$ & $8 / 32 \mathrm{~min}$ & $8 / 96 \mathrm{~min}$ & & \\
\hline 04-12 Aug. & 329 & 325 & 431 & $q$ & 378 & 387 & 371 & 58.2 \\
\hline 13-20 Aug. & 296 & 333 & 462 & $q$ & 461 & 399 & 337 & 36.7 \\
\hline 21-29 Aug. & 310 & 332 & 458 & $q$ & 464 & 398 & 327 & 38.2 \\
\hline 01-31 Aug. & 314 & 332 & 450 & $\mathrm{q}$ & 428 & 396 & 350 & 38.6 \\
\hline $01-30 \mathrm{Sept}$. & 271 & 331 & 453 & $q$ & 476 & 423 & 332 & 26.0 \\
\hline $01-31$ Oct. & 299 & 345 & 458 & $q$ & 478 & 442 & 341 & 18.5 \\
\hline $\begin{array}{l}\text { 01-15 Nov. } \\
\text { 01 Aug.- }\end{array}$ & 343 & 379 & 432 & 1 & 432 & 411 & 353 & 48.5 \\
\hline 15 Nov. & 306 & 346 & 448 & $q$ & 453 & 418 & 344 & 27.5 \\
\hline
\end{tabular}

${ }^{1}$ ANOVA: analysis of variance on the differences between continuous $\mathrm{CO}_{2}$ concentrations (treatments $200,340$ and $500 \mathrm{ppm}): 1=$ linear component significant, $\mathrm{q}=$ quadratic component significant, $\mathrm{n}=\mathrm{no}$ significance at $P=0.05$.

2 Least significant difference, calculated over all treatments.

is clear that it was not always possible to maintain the setpoints, especially the setpoint of $200 \mathrm{ppm}$. This was due to the high ventilation in the autumn period and the insufficient capacity of the $\mathrm{CO}_{2}$ filtering installations. Remarkable and unexpected was the high average $\mathrm{CO}_{2}$ level in the control treatment, especially in early August. This can be explained partly by $\mathrm{CO}_{2}$ release from the soil and partly by influx of $\mathrm{CO}_{2}$ from the environment. In this region, close to the industrial area of Rotterdam, the ambient level of $\mathrm{CO}_{2}$ is regularly high.

\section{Vegetative growth}

The vegetative growth was determined on five dates during the experiment. The results of the last observation ( 22 October), when the differences were most obvious, are given in Table 2.

Some parameters which are calculated from the observed vegetative data show clear differences: the dry matter content of the leaves increased at higher $\mathrm{CO}_{2}$ levels; the Specific Leaf Area (leaf area per dry weight of leaves) and the Leaf Area Ratio (leaf area per dry weight of plant), decreased with increasing $\mathrm{CO}_{2}$ levels.

Some observed data (number of leaves, leaf area) showed a decrease with increasing $\mathrm{CO}_{2}$ levels, especially if only the continuous $\mathrm{CO}_{2}$ treatments were considered. Other parameters (fresh and dry weights of leaves and stems) only indicated a tendency towards less vegetative growth at higher $\mathrm{CO}_{2}$ levels. A statistical analysis could not confirm the tendency however, since the number of plants (two per compartment) and the number of replicates (two compartments) were too small. Moreover, the differences between treatments in realized $\mathrm{CO}_{2}$ levels (Table 1) were relatively small and the variances between individual sweet pepper plants are great. 
Table 2. Vegetative plant parameters of sweet pepper, measured on 22 October at six $\mathrm{CO}_{2}$ treatments, averaged over two compartments and two plants per compartment. Leaf area in $\mathrm{dm}^{2}$ per plant; weights in ger plant: dry matter (DM) content in \%. Specific Leaf Area (SLA) and Leaf Area Ratio (LAR) in $\mathrm{cm}^{2} \mathrm{~g}^{-1}$.

\begin{tabular}{|c|c|c|c|c|c|c|c|c|}
\hline \multirow[t]{2}{*}{ Parameter } & \multicolumn{4}{|c|}{ Continuous $\mathrm{CO}_{2}$ levels } & \multicolumn{2}{|c|}{ Intermittent } & \multirow[t]{2}{*}{ Control } & \multirow{2}{*}{$\begin{array}{l}\mathrm{LSD}^{2} \\
(P<0.05)\end{array}$} \\
\hline & $200 \mathrm{ppm}$ & $340 \mathrm{ppm}$ & $500 \mathrm{ppm}$ & ANOVA' & $8 / 32 \mathrm{~min}$ & $8 / 96 \mathrm{~min}$ & & \\
\hline $\begin{array}{c}\text { Number of } \\
\text { leaves }\end{array}$ & 204.8 & 173.3 & 159.5 & 1 & 200.3 & 171.8 & 163.8 & n.s. \\
\hline Leaf area & 130.8 & 110.8 & 99.6 & 1 & 113.4 & 109.1 & 94.8 & n.s. \\
\hline $\begin{array}{c}\text { Fresh wt } \\
\text { leaves }\end{array}$ & 289.0 & 247.3 & 235.5 & $\mathrm{n}$ & 259.0 & 239.9 & 216.8 & n.s. \\
\hline $\begin{array}{c}\text { Fresh wt } \\
\text { stem }\end{array}$ & 400.3 & 325.3 & 328.8 & $\mathrm{n}$ & 396.0 & 340.3 & 324.5 & n.s. \\
\hline $\begin{array}{l}\text { Dry wt } \\
\text { leaves }\end{array}$ & 40.2 & 36.3 & 35.8 & $\mathrm{n}$ & 39.8 & 34.3 & 32.9 & n.s. \\
\hline $\begin{array}{l}\text { Dry wt } \\
\text { stem }\end{array}$ & 51.3 & 45.8 & 45.6 & $\mathrm{n}$ & 55.3 & 44.5 & 46.2 & n.s. \\
\hline DM leaves & 13.9 & 14.7 & 15.2 & 1 & 15.3 & 14.3 & 15.2 & 0.95 \\
\hline DM stem & 12.8 & 14.1 & 13.9 & $\mathrm{n}$ & 13.9 & 13.1 & 14.2 & n.s. \\
\hline SLA & 326.0 & 305.0 & 278.1 & 1 & 285.7 & 318.6 & 288.3 & 20.4 \\
\hline LAR & 143.7 & 135.2 & 122.3 & 1 & 120.3 & 138.6 & 120.0 & 15.2 \\
\hline
\end{tabular}

1.2 See Table 1 .

Table 3. Fruit set of sweet pepper (numbers of flowers set per $\mathrm{m}^{2}$ ) at six $\mathrm{CO}_{2}$ treatments, counted at three dates of defloration/defruiting, averaged per treatment ( = two compartments).

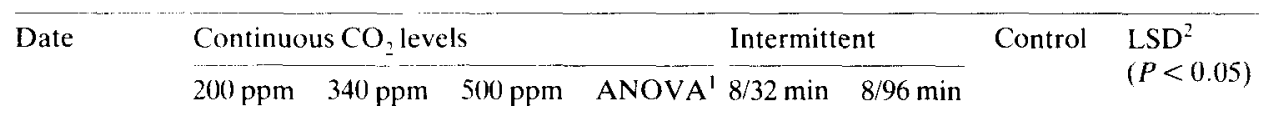

Non-cumulative

$\begin{array}{lrrrcrrrr}\text { 13 Aug. } & 5.8 & 8.8 & 13.3 & \mathrm{n} & 7.8 & 8.9 & 9.0 & \text { n.s. } \\ \text { 21 Aug. } & 13.5 & 18.3 & 26.0 & 1 & 22.8 & 19.7 & 16.8 & 6.2 \\ \text { 30 Aug. } & 8.0 & 11.6 & 15.9 & \mathrm{n} & 17.8 & 12.9 & 9.8 & \text { n.s. }\end{array}$

\section{Cumulative}

\begin{tabular}{lllllllll}
21 Aug. & 19.3 & 27.2 & 39.4 & 1 & 30.6 & 28.6 & 25.8 & 10.5 \\
30 Aug. & 27.3 & 38.8 & 55.3 & 1 & 48.4 & 41.5 & 35.6 & 17.2 \\
\hline
\end{tabular}

1.2 See Table 1 .

\section{Generative growth}

Fruit set was increased by elevated $\mathrm{CO}_{2}$ concentration, as shown in Table 3. Per date of defloration/defruiting, the results were not always significantly different if all treatments were considered, but the differences over the three continuous $\mathrm{CO}_{2}$ 
concentrations $(200,340$ and $500 \mathrm{ppm})$ were significant, as follows from the probabilities. Also the accumulated fruit setting data differed significantly. In Fig. 1 the fruit set in each compartment is related to the average $\mathrm{CO}_{2}$ level, measured in the compartment during the corresponding period (mentioned in the figure), the period which probably is important for the fruit set.

Also with respect to the yield, the favourable effect of $\mathrm{CO}_{2}$ is obvious. The number of harvested fruits increased with increasing $\mathrm{CO}_{2}$ concentrations (Table 4), while the average fruit weights were not significantly different. The second-class fruits are not included in the data in Table 4 . The amounts of second-class fruits ranged from 1.5 to $2.7 \%$ of the total yield and they were not significantly related to the $\mathrm{CO}_{2}$ concentrations. In Fig. 2, for each compartment, the number of fruits harvested per $\mathrm{m}^{2}$ is related to the average measured $\mathrm{CO}_{2}$ concentration in the preceding period.

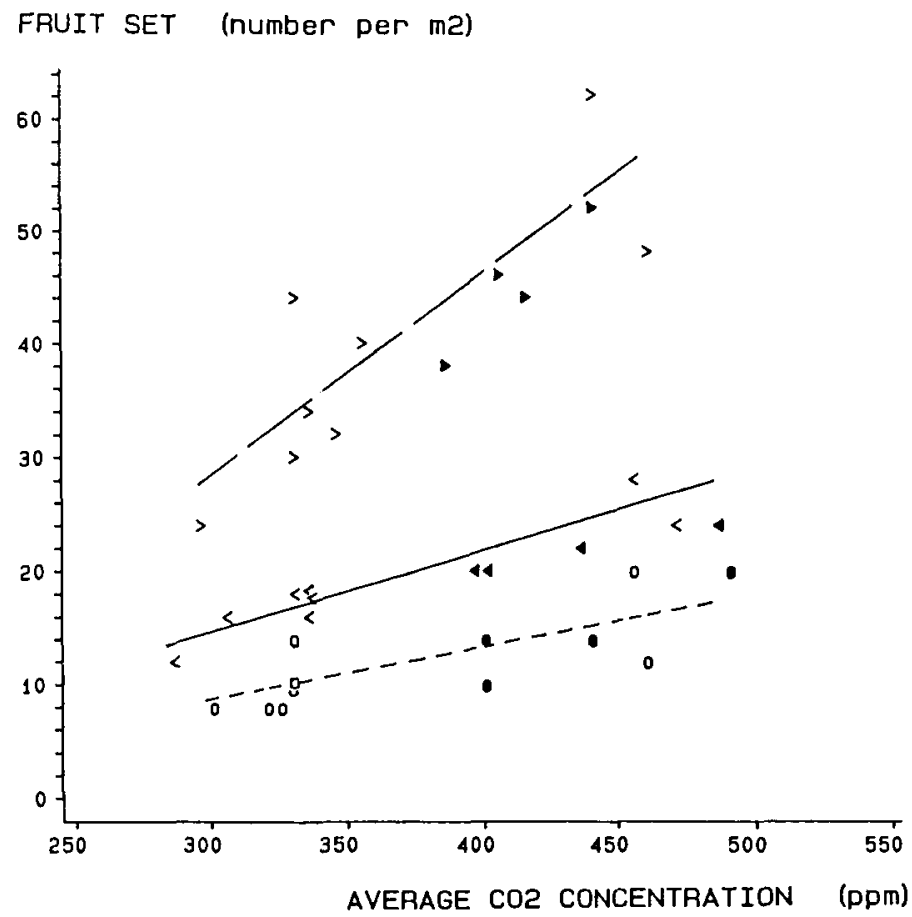

Fig. 1. Fruit set of sweet pepper (number per $\mathrm{m}^{2}$ ) versus average, measured $\mathrm{CO}_{2}$ level (ppm) in the corresponding period, data per compartment. Linear regression lines $(Y=a X+b)$ are fitted through the observations at continuous $\mathrm{CO}$ treatments $(200,340$ and $500 \mathrm{ppm})$ and control only. Open symbols: continuous $\mathrm{CO}_{2}$ treatments $(200,340$ and $500 \mathrm{ppm})$ and control. Filled symbols: intermittent $\mathrm{CO}_{2}$ treatments.

$1 .-<$ setting 14-21 Aug. vs. $\mathrm{CO}_{2}$ of 13-20 Aug.; $a=0.072, b=-6.9, r=0.62$.

2. - - - setting 22-30 Aug. vs. $\mathrm{CO}_{2}$ of 21-29 Aug.; $a=0.046, b=-5.0, r=0.77$.

3. $-\rightarrow$ cumulative setting until 30 Aug. vs. $\mathrm{CO}_{2}$ of $4-29$ Aug.; $a=0.177, b=-24.9, r=0.68$. 
Table 4. Cumulative yield of sweet pepper (number of red fruits per $\mathrm{m}^{2}$ ) at six $\mathrm{CO}_{2}$ treatments, averaged per treatment ( $=$ two compartments).

\begin{tabular}{|c|c|c|c|c|c|c|c|c|}
\hline \multirow[t]{2}{*}{ Date } & \multicolumn{4}{|c|}{ Continuous $\mathrm{CO}_{2}$ levels } & \multicolumn{2}{|c|}{ Intermittent } & \multirow[t]{2}{*}{ Control } & \multirow{2}{*}{$\begin{array}{l}\mathrm{LSD}^{2} \\
(P<0.05\end{array}$} \\
\hline & $200 \mathrm{ppm}$ & $340 \mathrm{ppm}$ & $500 \mathrm{ppm}$ & ANOVA $^{\prime}$ & $8 / 32 \mathrm{~min}$ & $8 / 96 \mathrm{~min}$ & & \\
\hline 1 Oct. $^{3}$ & 0.8 & 3.4 & 4.2 & 1 & 1.8 & 1.9 & 1.6 & n.s. \\
\hline 29 Oct. $^{4}$ & 7.4 & 10.5 & 14.5 & 1 & 12.9 & 9.5 & 8.9 & 4.26 \\
\hline 19 Nov. ${ }^{4}$ & 13.4 & 16.3 & 21.3 & 1 & 20.0 & 17.9 & 15.5 & 2.24 \\
\hline 19 Nov. all 5 & 16.2 & 18.4 & 23.6 & l & 22.4 & 20.4 & 18.3 & 2.14 \\
\hline
\end{tabular}

1.2 See Table 1.

${ }^{3}$ Only fruits from the first fruit set treatment.

${ }^{4}$ Data from all fruit set treatments.

4.5 All mature fruits, including green and red/green.

In both figures ( 1 and 2$)$ the positive correlation between $\mathrm{CO}_{2}$ concentration and fruit set and yield, respectively, is visible, especially for the non-intermittent $\mathrm{CO}_{2}$ treatments, through which the linears are fitted (treatments 200, 340 and $500 \mathrm{ppm}$, and the control treatment).

YIELD (number per ma)

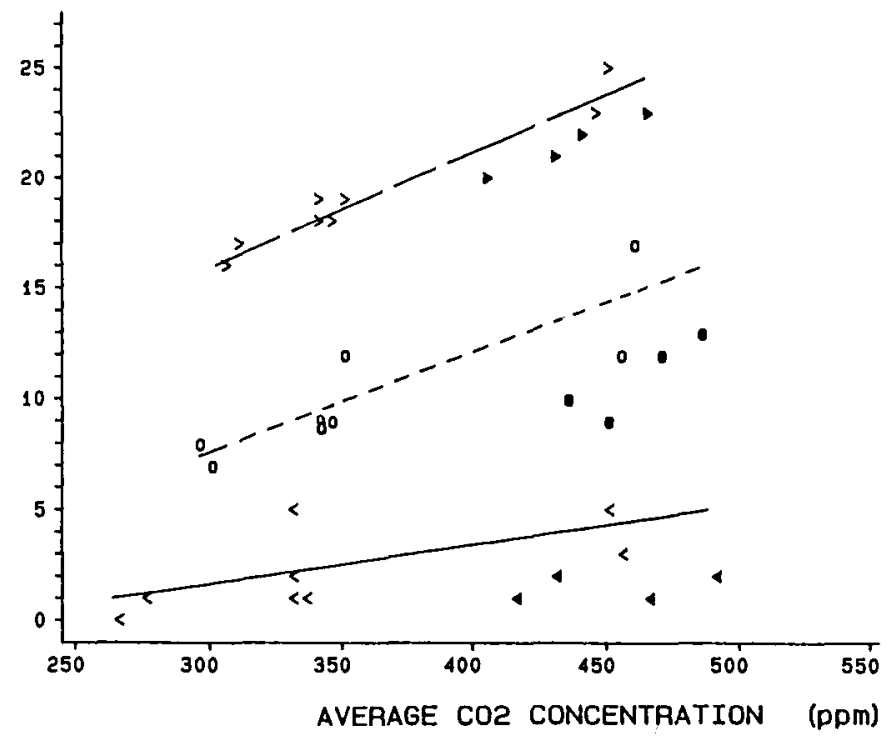

Fig. 2. Yield of sweet pepper (number of fruits per $\mathrm{m}^{2}$ ) versus average, measured $\mathrm{CO}_{2}$ concentration $(\mathrm{ppm})$ in previous period. Observations per compartment. Symbols and linears as in Fig. 1.

1 . - $<4$ yield at 1 Oct. vs. $\mathrm{CO}_{2}$ in Sept $; a=0.018, b=-3.7, r=0.65$.

2. - - $\mathrm{O}$ yield until 29 Oct. vs. $\mathrm{CO}_{2}$ in Oct.; $a=0.045, b=-5.9, r=0.86$.

3 . $->$ yield until 19 Nov. vs. $\mathrm{CO}_{2}$ of 1 Aug. -15 Nov.; $a=0.053, b=0.1, r=0.96$. 


\section{Discussion}

\section{Crop response}

A positive effect of carbon dioxide on fruit set was observed and this may be explained by a direct positive effect of $\mathrm{CO}_{2}$ on photosynthesis. An increased photosynthesis rate makes more assimilates available for the flowers and fruits, which are strong sinks for assimilates. This explanation is based on the work of other authors: Calvert \& Slack (1975) found a clear correlation between $\mathrm{CO}_{2}$ concentration and average number of fruits per truss at the first ten trusses of tomato. The authors ascribe this phenomenon to enhanced rates of net assimilation and of carbon transport from leaves to fruits (sinks) of $\mathrm{CO}_{2}$-enriched plants. Acock \& Pasternak (1986), referring to a number of literature sources, described an increase of number of flowers and fruits of some crops at elevated $\mathrm{CO}_{2}$ levels, caused by increase of photosynthesis.

The increase of yield at higher $\mathrm{CO}_{2}$ levels, as found in this experiment, is thought to be partly a result of the better fruit set and partly of a better supply with assimilates of the fruits during the fruit growth period.

An increase in dry matter content of leaves at high $\mathrm{CO}_{2}$ concentrations, which was observed in this study, has also been reported by Klapwijk \& Wubben (1984) for young tomato, cucumber and sweet pepper plants. The observation that the leaf area per unit dry weight (both of leaves and of total plant: SLA and LAR) was significantly smaller at higher $\mathrm{CO}_{2}$ concentrations, implies that the plants had thicker leaves and heavier stems, relative to the leaf area, at higher $\mathrm{CO}_{2}$ levels. This was also found by other authors (Hurd, 1968, for tomato, and Jolliffe \& Ehret, 1984, for bean). Acock \& Pasternak (1986) ascribe the decrease of SLA at higher $\mathrm{CO}_{2}$, as observed in some crops, to accumulation of carbohydrates in leaves.

A tendency to a decreased vegetative growth at elevated $\mathrm{CO}_{2}$ levels was observed and this may be explained by competition between vegetative and generative organs (Hall, 1977). Since fruits are strong sinks, it is perceptible that in crops with a high fruit load (grown at higher $\mathrm{CO}_{2}$ levels), the vegetative growth is hampered more than in crops where less fruits are set (grown at lower $\mathrm{CO}_{2}$ levels).

\section{Intermittent $\mathrm{CO}_{2}$ enrichment}

From the results on fruit set and yield related to the average carbon dioxide concentrations, it appeared that intermittent enrichment seemed slightly less effective than enrichment to a constant $\mathrm{CO}_{2}$ level. This can be seen in Fig. 2 (and less clearly in Fig. 1), where the yield (respectively fruit set) at intermittent dosing treatments was below the linears fitted through the continuous dosing treatments. So the suggestion of Mortensen (1984) that the crop responds more efficiently to intermittent $\mathrm{CO}_{2}$ than to continuous enrichment, was not confirmed in this experiment. The papers of this author were based on experiments with Chrysanthemum and Saintpaulia in growth chambers.

Our negative results are also in contrast with the expectation of Enoch (1984), al- 
though the method proposed by this author was not applied in the same way in our experiment. According to Enoch (1984) also the ventilation should be intermittent . In order to avoid possible side effects caused by this measure (e.g. on temperature) and regarding a practical application, we applied continuous ventilation. The saving on use of $\mathrm{CO}_{2}$ was not recorded exactly. The concept of optimal use of $\mathrm{CO}_{2}$, which was the reason for Enoch (1984) to apply intermittent enrichment, was studied further under practical conditions in other work (Challa \& Schapendonk, 1986; Nederhoff, 1988).

\section{References}

Acock, B. \& D. Pasternak, 1986. Effects of $\mathrm{CO}_{2}$ concentration on composition, anatomy and morphology of plants. In: H. Z. Enoch \& B. A. Kimball (Eds), Carbon dioxide enrichment of greenhouse crops. Vol. II. Physiology, yield and economics, p. 41-52. CRC Press Inc., Boca Raton, Florida, USA.

Berkel. N. van, 1986. CO, enrichment in The Netherlands. In: H. Z. Enoch \& B. A. Kimball (Eds). Carbon dioxide enrichment of greenhouse crops. Vol. I, Status and $\mathrm{CO}_{2}$ sources, p. 17-33. CRC Press Inc., Boca Raton, Florida, USA.

Calvert. A. \& G. Slack, 1975. Effects of carbon dioxide enrichment on growth, development and yield of glasshouse tomatoes. I. Responses to controlled concentrations. Journal of Horticultural Science 50: $61-71$.

Challa. H. \& A. H. C. M. Schapendonk, 1986. Dynamic optimalization of the $\mathrm{CO}_{2}$ concentration in relation to climate control in greenhouses. In: H. Z. Enoch \& B. A. Kimball (Eds), Carbon dioxide enrichment of greenhouse crops. Vol. I, Status and $\mathrm{CO}_{2}$ sources, p. 147-160. CRC Press Inc., Boca Raton. Florida. USA.

Enoch, H. Z., 1984. Carbon dioxide uptake efficiency in relation to crop intercepted solar radiation, Acta Horticulturae 162: 137-147.

Hall, A. J.. 1977. Assimilate source-sink relationships in Capsicum annuum L. I. The dynamics of growth in fruiting and deflorated plant. Australian Journal of Plant Physiology 4: 623-636.

Hurd, R. G. 1968. Effects of $\mathrm{CO}_{2}$ enrichment on the growth of young tomato plants in low light. Annals of Botany 32: 531-542.

Jolliffe. P. A. \& D. L. Ehret, 1984. Analysis of the growth responses of bean plants to elevated $\mathrm{CO}_{2}$ concentrations. Acta Horticulturae 162: 255-263.

Kimball, B. A., 1986. Influence of elevated $\mathrm{CO}_{2}$ on crop yield. In: H. Z. Enoch \& B. A. Kimball (Eds). Carbon dioxide enrichment of greenhouse crops. Vol. II, Physiology, yield and economics, p. 105115. CRC Press Inc., Boca Raton, Florida, USA.

Klapwijk, D. \& C. F. M. Wubben, 1984. The effect of carbon dioxide on growth of young tomato, cucumber and sweet pepper plants. Acta Horticulturae 162: 249-254.

Mortensen. L. M. 1984. Photosynthetic adaptation in $\mathrm{CO}_{2}$ enriched air and the effect of intermittent $\mathrm{CO}_{2}$ application in greenhouse plants. Acta Horticulturae 162: 153-158.

Nederhoff, E. M., 1988. Dynamic optimization of the $\mathrm{CO}_{2}$ concentrations in greenhouses: an experiment with cucumber (Cucumis sativus L.). Acta Horticulturae (in press). 